University of Wollongong

Research Online

Faculty of Engineering and Information

Faculty of Engineering and Information

Sciences - Papers: Part A

Sciences

$1-1-2015$

Influence of loading conditions during tensile testing on acoustic emission

Turbadrakh Chuluunbat

University of Wollongong, tc970@uowmail.edu.au

Cheng Lu

University of Wollongong, chenglu@uow.edu.au

Andrii Kostryzhev

University of Wollongong, andrii@uow.edu.au

A Kiet Tieu

University of Wollongong, ktieu@uow.edu.au

Follow this and additional works at: https://ro.uow.edu.au/eispapers

Part of the Engineering Commons, and the Science and Technology Studies Commons

Research Online is the open access institutional repository for the University of Wollongong. For further information contact the UOW Library: research-pubs@uow.edu.au 


\title{
Influence of loading conditions during tensile testing on acoustic emission
}

\begin{abstract}
The Acoustic Emission (AE) monitoring technique is widely used in mechanical and material research for detection of plastic deformation, fracture initiation and crack growth. However, the influence of $A E$ features (such as signal amplitude, frequency, rise time and duration) on the fracture parameters (such as brittle or ductile mode of propagation and fracture propagation speed) is not completely understood. In this paper, the effect of loading conditions on fracture behavior was studied using AE monitoring during tensile testing of an aluminum alloy specimen. The fracture development was observed using a high speed video camera and was analyzed using the finite element method. The hardware and software produced by Physical Acoustics Corporation (USA) was used. Variations in AE parameters were analyzed and correlated to the stress-Strain curves obtained during testing. It is shown that the strain rate and the presence of a crack (modeled by a notch on the sample), affect the fracture mode (brittle or ductile) and a relative amount of the mode dependent $A E$ signatures.
\end{abstract}

\section{Keywords}

emission, tensile, during, acoustic, conditions, loading, testing, influence

Disciplines

Engineering | Science and Technology Studies

\section{Publication Details}

Chuluunbat, T., Lu, C., Kostryzhev, A. \& Tieu, K. (2015). Influence of loading conditions during tensile testing on acoustic emission. Key Engineering Materials, 626 121-126. 


\title{
Influence of loading conditions during tensile testing on acoustic emission
}

\author{
TURBADRAKH Chuluunbat ${ }^{\mathrm{a}}{ }^{*}$, CHENG Lu $^{\mathrm{b}}$, ANDRII Kostryzhev $^{\mathrm{c}}$ and KIET \\ Tieu $^{d}$
}

School of Mechanical, Materials and Mechatronics Engineering, University of Wollongong,

NSW 2522, Australia

a ${ }^{\star}$ tc970@uowmail.edu.au, bchenglu@uow.edu.au, ${ }^{c}$ andrii@uow.edu.au, ${ }^{\text {d}}$ ktieu@uow.edu.au

Keywords: ductile and brittle metal fracture, acoustic emission monitoring, tensile testing, fracture propagation

\begin{abstract}
The Acoustic Emission (AE) monitoring technique is widely used in mechanical and material research for detection of plastic deformation, fracture initiation and crack growth. However, the influence of AE features (such as signal amplitude, frequency, rise time and duration) on the fracture parameters (such as brittle or ductile mode of propagation and fracture propagation speed) is not completely understood. In this paper, the effect of loading conditions on fracture behavior was studied using AE monitoring during tensile testing of an aluminum alloy specimen. The fracture development was observed using a high speed video camera and was analyzed using the finite element method. The hardware and software produced by Physical Acoustics Corporation (USA) was used. Variations in AE parameters were analyzed and correlated to the stress-strain curves obtained during testing. It is shown that the strain rate and the presence of a crack (modeled by a notch on the sample), affect the fracture mode (brittle or ductile) and a relative amount of the mode dependent AE signatures.
\end{abstract}

\section{Introduction}

Acoustic Emission (AE) is a phenomenon in which transient stress/ displacement waves are generated following rapid release of energy from localized sources such as crack initiation sites, fracture propagation and dislocation in metals [1, 2]. The elastic energy is transmitted through the material in the form of transient elastic waves and can be detected by sensors on the surface of the specimen. The sensor converts elastic waves to the electric signals which are then processed and analyzed by special hardware and software. AE signal analysis is often complicated due to background noise generated by friction or machine work [3]. AE monitoring has been widely used to investigate the fracture behaviour of metals (Table 1). Wadley et al. used AE monitoring during tensile testing of carbon ferritic steel to detect burst signal near the yield point [4]. Mukhopadhya et al. [5, 6] studied AE generated by the dislocation movement in an austenitic stainless steel sample. A dislocation movement model describing the AE wave from macro-yielding was obtained. Some researchers used the $\mathrm{AE}$ monitoring technique to investigate the $\mathrm{AE}$ signal associated with crack growth in rail steel [3] and in A572-G50 steel [7]. Some authors studied the relationship between $\mathrm{AE}$ features (such as signal amplitude, frequency, energy and duration) and mechanical parameters (load, stress and crack growth) during tensile deformation of notched or plain specimens [8-11]. However, the quantitative influence of AE parameters on the fracture parameters (such as brittle or ductile mode of propagation and fracture behaviour) is not completely understood to date. In the present study, the effect of loading conditions on fracture initiation and propagation was studied using AE monitoring and observed using a high-speed video camera during tensile testing of an aluminium alloy sample. In addition, notched specimen was simulated to investigate the fracture initiation point using a finite element method (FEM). The stress-strain curves were correlated to the $\mathrm{AE}$ parameters to obtain a dependence of the AE features on the fracture propagation parameters. 
Table 1 Characteristic features of AE waveform from various sources.

\begin{tabular}{|c|c|c|c|c|c|c|c|c|}
\hline \multirow[t]{2}{*}{ AE sources } & \multirow[t]{2}{*}{ Factors } & \multicolumn{6}{|c|}{ AE waveform parameters } & \multirow[t]{2}{*}{ Ref } \\
\hline & & Amplitude & Frequency & Duration & Rise time & Count & Waveform & \\
\hline \multirow[t]{2}{*}{$\begin{array}{c}\text { Fracture } \\
\text { modes }\end{array}$} & Ductile fracture & Low & Low & Long & Low & Low & $\begin{array}{l}\text { Continuous } \\
\text { signal }\end{array}$ & \multirow[t]{2}{*}[3]{} \\
\hline & Brittle fracture & High & High & Short & High & High & Burst signal & \\
\hline \multirow[t]{2}{*}{$\begin{array}{l}\text { Material } \\
\text { behavior }\end{array}$} & $\begin{array}{l}\text { Plastic } \\
\text { deformation }\end{array}$ & Low & low & long & Low & - & $\begin{array}{l}\text { Continuous } \\
\text { signal }\end{array}$ & {$[8]$} \\
\hline & $\begin{array}{l}\text { Crack initiation } \\
\text { and propagation }\end{array}$ & High & High & Short & High & - & Burst signal & $\begin{array}{l}{[3]} \\
{[10]}\end{array}$ \\
\hline \multirow[t]{2}{*}{ Crack type } & Tensile mode-I & High & High & Short & high & & Longitudinal & \multirow[t]{2}{*}[1]{} \\
\hline & Shear mode-II & Low & low & long & low & & Shear wave & \\
\hline \multirow{2}{*}{$\begin{array}{c}\text { Strain rate } \\
\text { effect }\end{array}$} & High Strain rate & High & - & - & - & - & - & \multirow{2}{*}{$\begin{array}{l}{[8]} \\
{[11]}\end{array}$} \\
\hline & Low strain rate & Low & - & - & - & - & - & \\
\hline
\end{tabular}

\section{Experimental procedure}

Tensile testing. The tensile tests were carried out using an Instron machine operating at ambient temperature. Various levels of strain rates were used for both single edge notched and plain

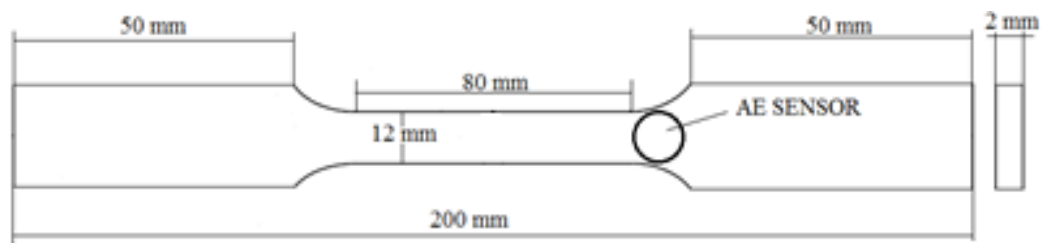

Fig. 1 The geometry of single edge notched specimen specimen: : $1.25 \times 10^{-4} \mathrm{~s}^{-1}, 2.5 \times 10^{-4} \mathrm{~s}^{-}$ $1, \quad 5.0 \times 10^{-4} \mathrm{~s}^{-1}, 1.25 \times 10^{-3} \mathrm{~s}^{-1}$ and $2.5 \times 10^{-3} \mathrm{~s}^{-1}$.At least three specimens were tested for each condition. The samples were prepared from an aluminum alloy plate and the tensile direction was parallel to the rolling direction. A $0.3 \mathrm{~mm}$ wide, $3 \mathrm{~mm}$ long (1/4 of the specimen width in the middle) notch was cut using wire cutting. The crack propagation during the test was observed using a MotionPro X3 high- speed camera with excellent resolution, with a maximum of $8500 \mu$ s exposure time and up to 300 of frames/sec recording rate.

AE monitoring. During the test, the $\mathrm{AE}$ was recorded using an $\mathrm{AE}$ acquisition system manufactured by Physical Acoustics Corporation (USA). The system consisted of a single channel

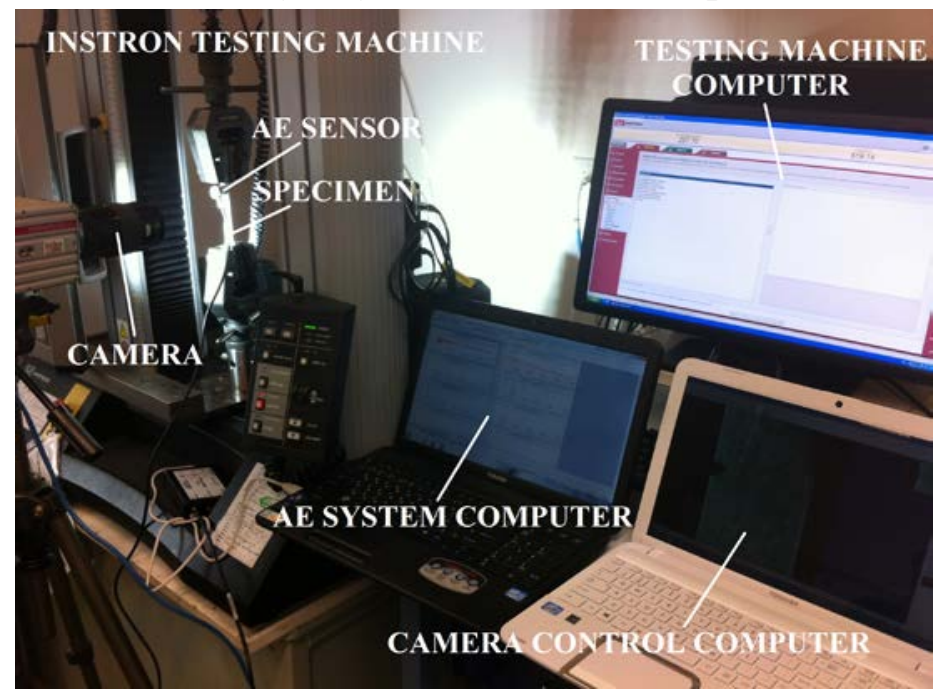

Fig. 2 The experimental setup of the tensile testing AE Digital Signal Conditioner (card) with a built-in low- noise preamplifier and a USB connection to a computer. One general- purpose wideband sensor (WS $\alpha$ ) was used in this study: the dimensions are 19mm OD and $21.4 \mathrm{~mm}$ height; operating frequency range is $100-1000 \mathrm{kHz}$ and temperature range is $-65^{\circ} \mathrm{C}$ to $+175{ }^{\circ} \mathrm{C}$. During testing the sensor was mounted on the specimen using ultrasound treatment gel as a coupling material to improve the signal quality. The experimental setup of the tensile testing is shown in Fig. 2. The variations in $\mathrm{AE}$ parameters were analyzed using the 'Average Hit Features' and 'Wave Form and Power Spectrum' methodologies and correlated to the stress-strain/load-time curves obtained during testing.

Fracture simulation. In this study, the single edge notched tensile specimen was modelled by using the finite element analysis software ANSYS/LS-DYNA. The simulation of ductile fracture problem and plastic flow localization was carried out by using of the Gurson-Tvergaard-Needleman (GTN) model that is applicable for most engineering alloys $[12,13]$. The GTN constitutive model can 
describe the influence of voids on the plasticity properties of a metal and can be incorporated in the finite element analysis to simulate the tensile behavior of an aluminum alloy specimen [14]. The tensile testing was carried out by pulling both ends of the specimen until the specimen fractured. An element length of $0.3 \mathrm{~mm}$ was used in the simulation. The model parameters used were: $\mathrm{q}_{1}=1.5$, $\mathrm{q}_{2}=1.0, \mathrm{f}_{\mathrm{f}}=0.06, \mathrm{f}_{\mathrm{c}}=0.015$; where: $\mathrm{q}_{1}, \mathrm{q}_{2}$ - the constant material parameters for predictions of the model into closer agreement with full numerical analysis of a periodic array of voids, $\mathrm{f}_{\mathrm{f}}$ - the void volume fraction at failure of the material, $\mathrm{f}_{\mathrm{c}^{-}}$critical void volume fraction;

\section{Results and discussion}

Variation in AE parameters along the stress-strain curve. For the AE signal analysis, the stressstrain curve was divided into three regions: 1- before the yield point, 2- between the yield point and the peak stress, and 3- after the peak stress. During testing of the notched specimen at a slow strain rate, the AE activity was recorded as shown in Fig. 3a: Region 1: Several hits were recorded before yielding due to the stress concentration around the notch tip leading to slow crack growth; Region 2: the AE activity decreased compared to Region 1; Region 3: the AE activity was stable accompanying a monotonous crack propagation. Towards the end of Region 3 the AE hit density increased following the completion of fracture. The main AE signals observed in this region had an amplitude up to $50 \mathrm{~dB}$ and an average frequency up to $500 \mathrm{kHz}$. During testing of the plain (without a notch) specimen at a slow strain rate, the AE activity was different compared to that for the notched specimen, as shown in Figure 3b: Region 1: No AE activity was recorded before the yield point, which can be explained by the weakness of signals coming from the elastic tension and the absence of fracture; Region 2: A degree of AE activity related to plastic deformation was detected in this region. The main signals had an amplitude up to $50 \mathrm{~dB}$ and an average frequency up to 250 $\mathrm{kHz}$.
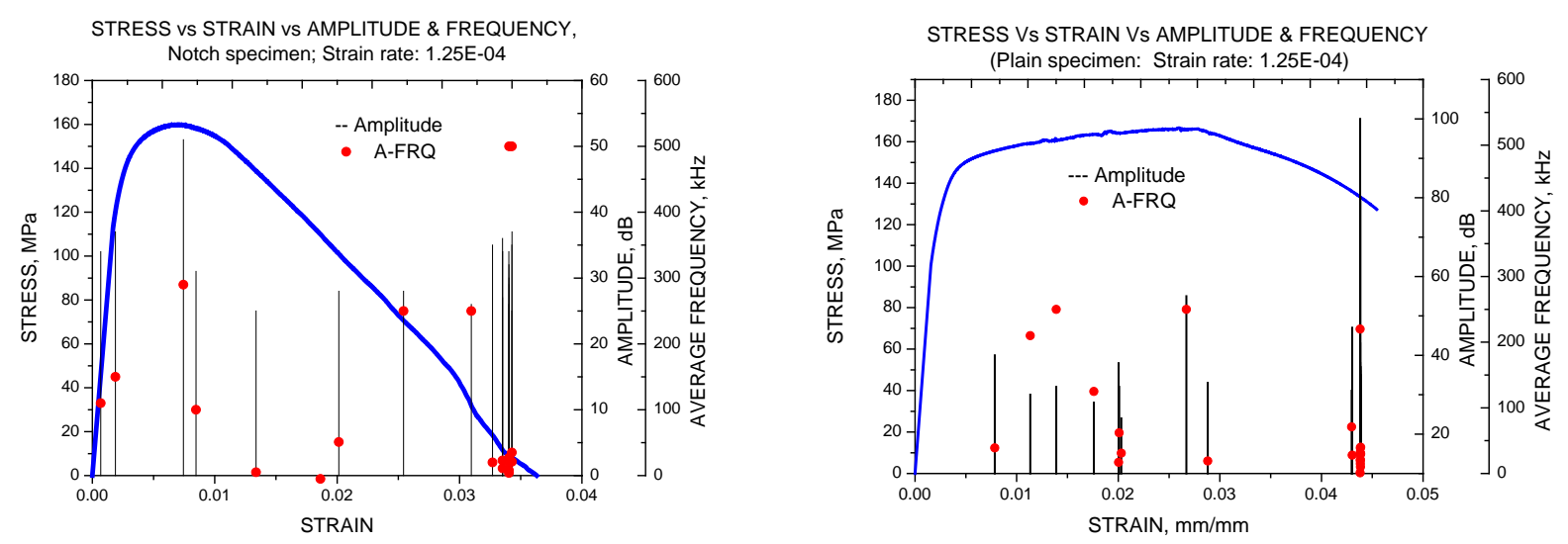

a

b

Fig. 3 Stress-Strain Curves vs AE amplitude and frequency at 1.25E-04 s ${ }^{-1}$ of strain rate: a) Single edge notched specimen, b) Plain specimen

Region 3: Necking was observed, with weak AE activity. However, a strong $\sim 100 \mathrm{~dB}$ signal was generated by the final fracture of the specimen. For the notched specimen with an increase in strain rate the $\mathrm{AE}$ hit density significantly increased around the yield point, decreased after the peak stress, but increased again in the period of final fracture (Fig.4 a). Amplitude of some hits reached 60dB, which is slightly higher compared to the slow strain rate tests. No significant variation in the AE average frequency was observed. For the plain specimen with an increase in strain rate the AE hit density increased significantly during the work- hardening period (Fig.4 b). This can be explained by a higher deformed volume of the plain specimen compared to the notched specimen. The AE signal amplitude slightly decreased down to a maximum of $60 \mathrm{~dB}$, compared to the $100 \mathrm{~dB}$ signals recorded at slower strain rate. The average frequency increased to up to $350 \mathrm{kHz}$, compared to the maximum $250 \mathrm{kHz}$ signals recorded at slower strain rate. 
Determination of fracture initiation by the AE technique. The FEM simulated and experimental stress-strain curves are compared and shown in Fig. 5. The stresses and strains were calculated using the reaction force and displacement data from the FEM results. As can be seen from Fig.5 and Table 2 the experimentally measured yield and maximum stress values are in a good agreement with the FEM calculated values.
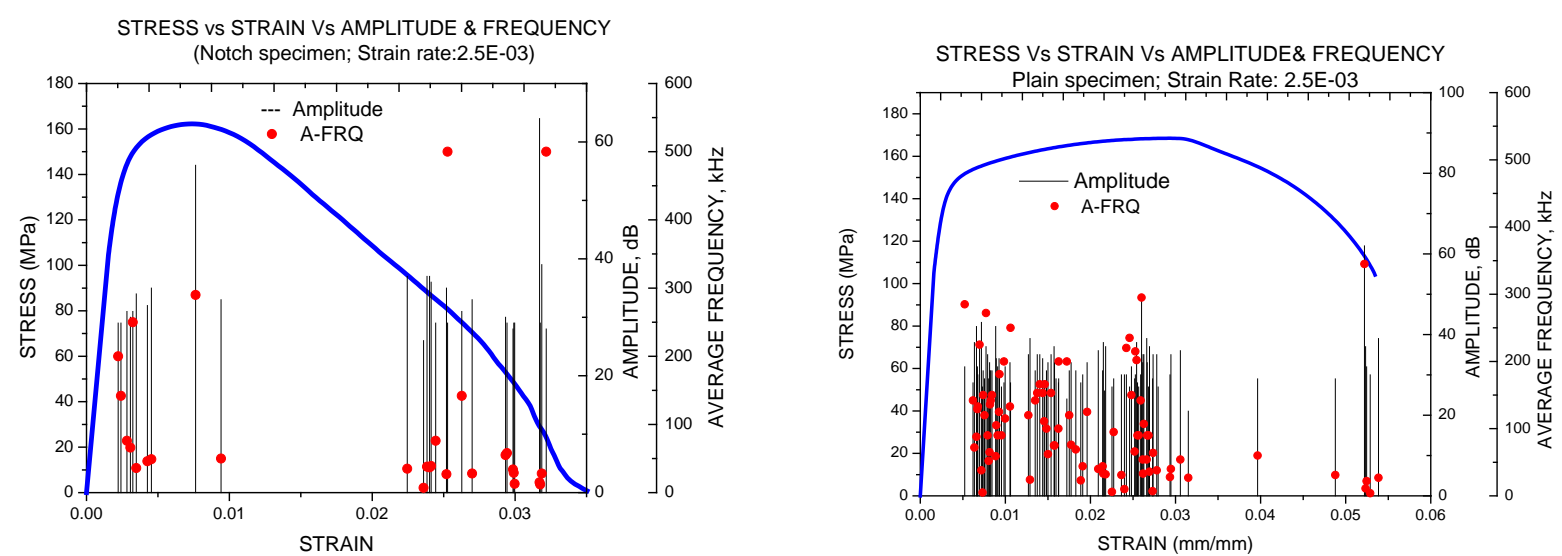

a

b

Fig. 4 Stress-Strain Curves vs AE amplitude and frequency at $2.5 \mathrm{E}-03 \mathrm{~s}^{-1}$ of strain rate: a) Single edge notched specimen, b) Plain specimen

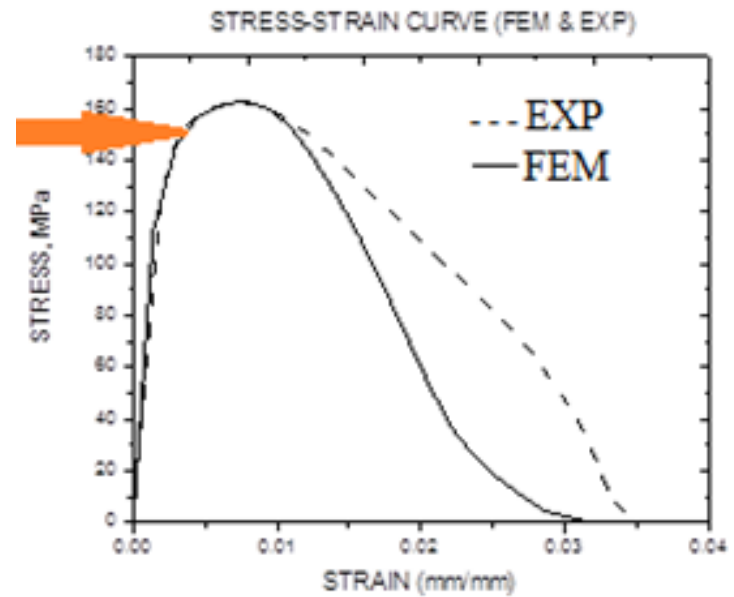

Fig. 5 The FEM simulated and experimental stressstrain curves for the single edge notch specimen tested at $2.5 \mathrm{E}-3 \mathrm{~s}^{-1}$ strain rate and Fracture initiation point obtained using FEM

Traditionally, it is assumed that fracture is initiated at maximum load/stress during tensile testing. However, the FEM simulation suggests that for the single edge notched specimen, the fracture initiation point occurred prior to the maximum point of stress-strain curve (Fig.5).This observation was supported by the AE signal analysis: the fracture initiation point of the tested aluminum alloy for the notched tensile specimen corresponded to the rapid change in $\mathrm{AE}$ activity, in particular an increase in the hit density, AE signal amplitude and frequency (Fig. 4 a). It can be seen from Table 2 that the crack initiation occurs during the testing just before the point of maximum load is reached. This crack corresponds to an AE signal with amplitude of $57 \mathrm{~dB}$ and frequency of $300 \mathrm{kHz}$.

Table 2 FEM and Experimental results for notched specimen

\begin{tabular}{|c|c|c|c|c|l|}
\hline & Max load & Yield stress & \multicolumn{2}{|c|}{ Fracture initiation point } & UTS \\
\cline { 4 - 5 } & {$[\mathrm{N}]$} & {$[\mathrm{MPa}]$} & Load [N] & Stress [MPa] & {$[\mathrm{MPa}]$} \\
\hline FEM simulation & 2936.1 & 112.56 & 2618.64 & 145.48 & 163.12 \\
\hline Experiment with AE & 2920.2 & 115 & 2907 & 161.8 & 162.23 \\
\hline
\end{tabular}

Correlation of the data obtained using FEM modelling to the data recorded using the high speed video camera has shown (Fig.6) the fracture phenomenon of the notched specimen and a typical plastic region under plane stress using the Von-Mises criterion.

AE waveform and power spectrum analysis. In the present study, a range of waveforms and power spectra was observed (Fig.7 and Table.3). Based on the stress-strain curve analysis, three regions could be distinguished in the $\mathrm{AE}$ amplitude-test time-average frequency distributions (Fig.7): I - before the yield point, II - between the yield point and the maximum stress, and III after the maximum stress till final failure. 


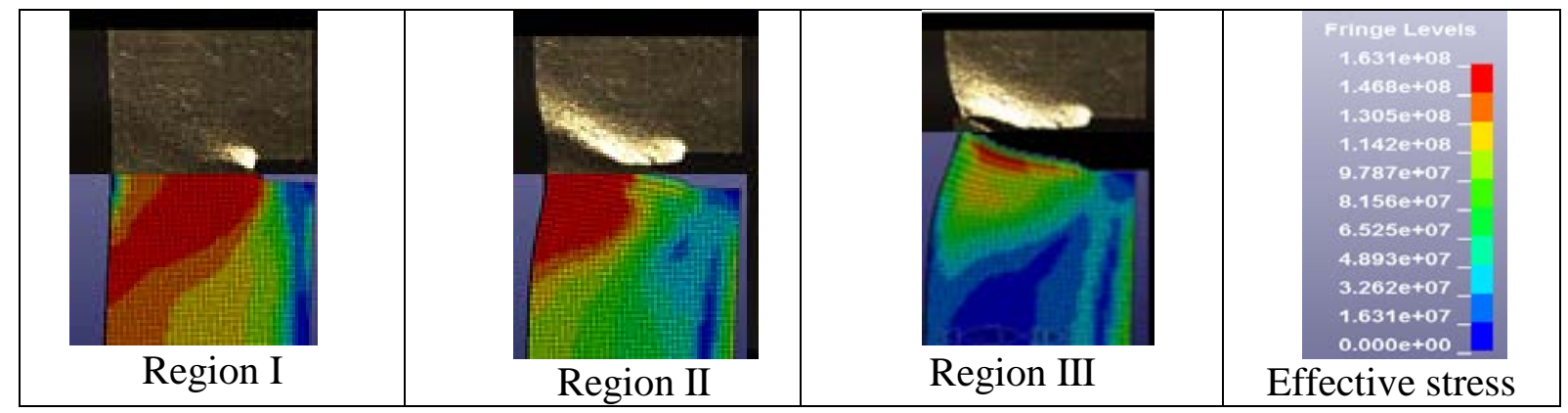

Fig. 6 Correlation of stress distributions obtained using FEM modeling to the high speed camera observations of crack growth for the single edge notch specimen.

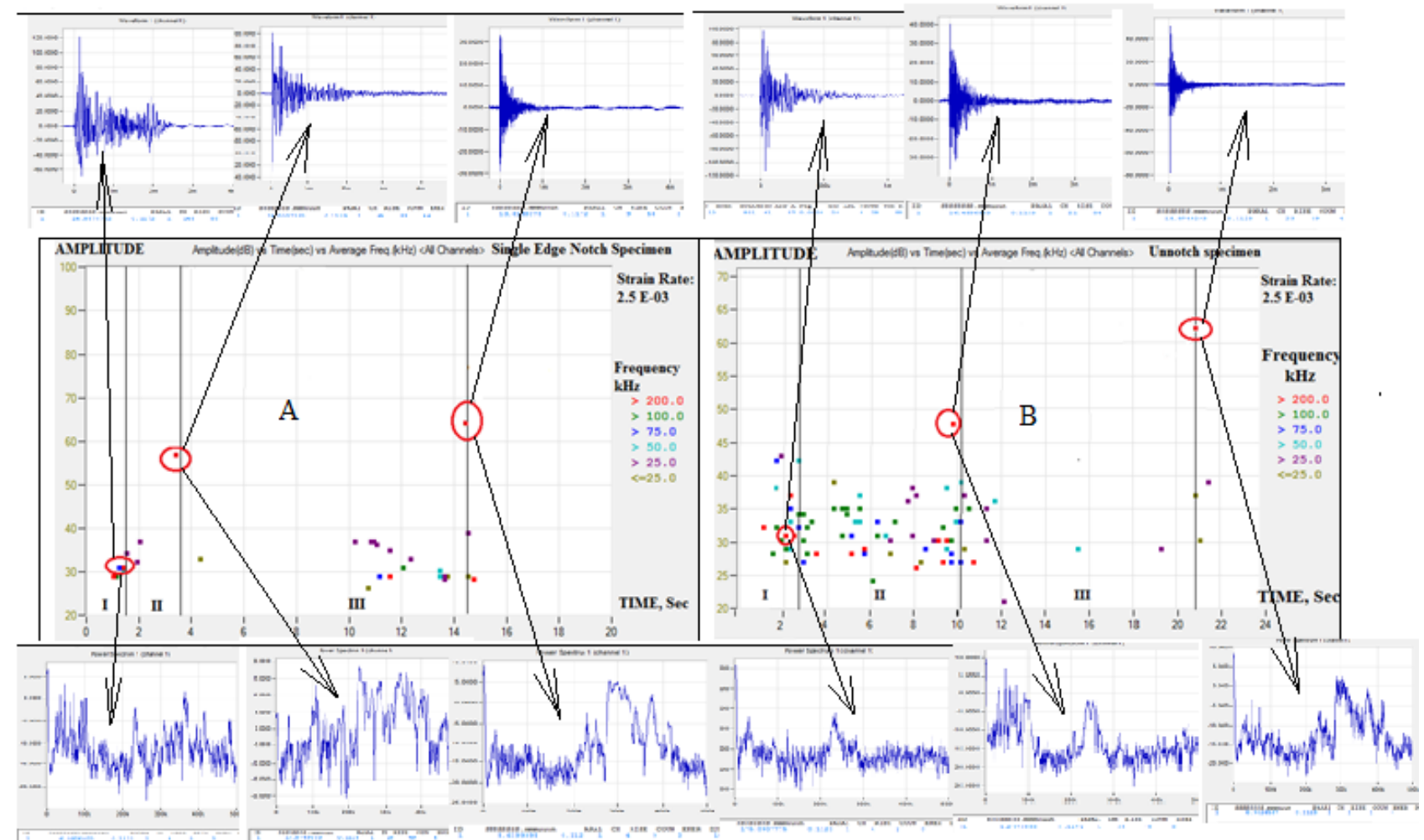

Fig. 7 The AE amplitude-average frequency-test time distribution with selected waveforms and power spectra corresponding to three regions of the stress-strain curve obtained during testing of single edge notched specimen (A) and plain specimen (B) at a strain rate of $2.5 \times 10^{-3} \mathrm{~s}^{-1}$ Observation of the AE waveforms did not show a significant variation in their shape for specimens of different type. However, the power spectra corresponding to the loading Regions I and II showed a larger number of high frequency peaks for the notched specimen, compared to that for the plain specimen. This can be explained by the variation in deformation propagation: in the notched specimen, crack growth is the dominant deformation feature, and the plain specimen deforms predominantly via the dislocation motion. During the final loading stage of (Region III on Fig.7) the power spectra looked similar for both specimen types, this can be related to the similarity in their fracture modes. As can be seen from Table 3, the power spectrum peaks occur at slightly higher frequencies for the notched specimen compared to these for the plain specimen.

\section{Conclusions}

AE monitoring during tensile testing of an aluminum alloy has shown the following:

1. The AE activity starts before the yield point for the notched specimen, due to stress concentration at the crack tip, and after the yield point for the plain specimen, due to 
dislocation motion. An increase in strain rate leads to increased AE activity, i.e. an increase in the AE hit density.

2. The fracture initiation point can be identified by the $\mathrm{AE}$ monitoring technique. For the notched specimen the fracture initiation led to an AE signal with $57 \mathrm{~dB}$ and $300 \mathrm{kHz}$.

3. For the tested aluminum alloy the peak frequency of power spectrum for brittle fracture was observed to be more than $200 \mathrm{kHz}$, and for ductile fracture to be lower than $35 \mathrm{kHz}$.

4. Scanning electron microscopy of the fracture surfaces is required to confirm the existence of brittle and ductile fracture modes in the studied aluminum alloy.

Table.3 Waveform parameters

\begin{tabular}{|c|c|l|c|c|}
\hline $\begin{array}{c}\text { Specimen } \\
\text { type }\end{array}$ & Region & \multicolumn{1}{|c|}{ Suggested cause of AE } & $\begin{array}{c}\text { Amplitude } \\
{[\mathrm{dB}]}\end{array}$ & $\begin{array}{c}\text { FFT power spectrum } \\
\text { frequency peak [kHz] }\end{array}$ \\
\hline $\begin{array}{c}\text { Single edge } \\
\text { notch }\end{array}$ & I & Elastic tension, void nucleation & $30-40$ & $50-150$ \\
\cline { 2 - 5 } & II & $\begin{array}{l}\text { Plastic deformation (voids growths and } \\
\text { coalescence ) }\end{array}$ & $<35$ & $>100$ \\
\cline { 2 - 5 } & III & Brittle crack growth & $>50$ & $200-500$ \\
\cline { 2 - 5 } & Ductile crack growth & $>35$ & $70-120$ \\
\hline \multirow{2}{*}{$\begin{array}{c}\text { Plain } \\
\text { specimen }\end{array}$} & I & Elastic tension & $<40$ & $>80$ \\
\cline { 2 - 5 } & III & Dislocation pile-up & $>30$ & $200-400$ \\
\cline { 2 - 5 } & & Brittle crack growth & $>30$ & $>90$ \\
\hline
\end{tabular}

\section{References}

[1] C.U. Grosse, M. Ohtsu, Acoustic emission testing, Springer, Heidelburg, 2008.

[2] B. Muravin, M.F. Carlos, Guide for development of acoustic emission application for examination of metal structure, J. Acoustic Emission. 29 (2011) 142-148.

[3] A.G. Kostryzhev, C.L. Davis, C. Roberts, Detection of crack growth in rail steel using acoustic emission, Ironmaking and Steelmaking. (2012) 1-6.

[4] H.N.G. Wadley, C.B Scruby, J.H.Speakes, Acoustic emission for physical examination of metals, International Metals Reviews. 2 (1980) 41-64.

[5] C.K. Mukhopadhyay, K.V. Rajkumar, T. Jayakumar, B. Raj, Study of tensile deformation behaviour of M250 grade maraging steel using acoustic emission. J. Mater. Sci. 45 (2010) 13711384.

[6] C.K. Mukhopadhyay, T. Jayakumar, B. Raj, K.K. Ray, The Influence of notch on the acoustic emission generated during tensile testing of nuclear grade AISI type 304 stainless steel, J. Mater. Sci and Eng. 276 (2000) 83-90.

[7] F.F. Barsoum, J. Suleman, A. Korcak, E.V.K. Hill, Acoustic emission monitoring and fatigue life prediction in axially loaded notched steel specimens,

[8] K. Ono, Current understanding of mechanisms of acoustic emission, J. Strain Analysis. 40 (2005) 1-15.

[9] H. Roy, N.Parida, S. Sivaprasad, S. Tarafder, K.K Ray, Acoustic emissions during fracture toughness tests of steel exhibiting varying ductility, J. Mater. Sci and Eng, 486 (2008) 562-571.

[10] Z. Kral, W. Horn, J. Steck, Crack propagation analysis using acoustic emission sensors for structural health monitoring system, The Scientific World Journal, 2013 (2013) 1-13.

[11] Z. Han, H. Lou, H. Wang, Effect of strain rate and notch on acoustic emission during the tensile deformation of a discontinuous yielding material, J. Mater Sci and Eng. 528 (2011) 4372-4380.

[12] A.L. Gurson, Continuum theory of ductile rupture by void nucleation and growth: part 1- yield criteria and flow rules for porous ductile media, J. Eng Mater. Tech. 99 (1977) 2-15.

[13] V. Tvergaard, A. Needleman, Analysis of the cup-cone fracture in a round tensile bar, Acta Metallurgica, 32 (1984) 157-169.

[14] B. Chen, X. Peng, J. Fan, S. Chen, Constitutive relation of casting aluminium alloy involving void evolution, J. Mater. Transactions. 46 (2005) 2997-3000. 